\title{
COGAF: A MAnagement Framework for Graduate AtTributes Assessment
}

\author{
${ }^{1}$ Abdelwahab Hamou-Lhadj, ${ }^{1}$ William Lynch, ${ }^{2}$ Ali Akgunduz \\ ${ }^{1}$ Department of Electrical and Computer Engineering \\ ${ }^{2}$ Department of Mechanical and Industrial Engineering \\ Concordia University \\ Montréal, QC, Canada \\ \{wahab.hamou-lhadj, william.lynch, ali.akgunduz\}@ concordia.ca
}

\begin{abstract}
The objective of this paper is to introduce COGAF (a Common Graduate Attributes management Framework), an end-to-end framework that can be used by Canadian higher-level education institutions for integrating and managing the assessment of CEAB (Canadian Engineering Accreditation Board) graduate attributes in a systematic manner. COGAF is designed around four components: Governance, People, Process, and Technology (GPPT). The governance component consists of a set of artifacts to guide the execution of a graduate attributes assessment project. It addresses the 'what should be done and why' questions. The PPT components address the 'how' and 'when'. The people component focuses on setting the right conditions to select, train, motivate, and retain the people who will operate COGAF. The process component focuses on the activities that need be carried out during the assessment project, whereas the technology component looks at tools (e.g., software applications) and technological platforms to support smooth execution of the assessment project.

COGAF relies on strong management practices. It is meant to be a turn-key solution to be used by any institution that wishes to engage in integrating graduate attributes in their programs. COGAF is easily customizable to fit the needs of small and large institutions.
\end{abstract}

Keywords: Graduate attributes: CEAB accreditation: management frameworks, teaching and program quality.

\section{INTRODUCTION}

The recent shift to an outcomes-based accreditation system is changing the way Canadian universities evaluate their engineering programs. The overall goal is to ensure that, at graduation, students acquire knowledge in 12 graduate attributes covering a wide range of competencies including communication skills, problem analysis, design, and so ${ }^{1}{ }^{1}$. These new changes impact not only single courses or programs, but the entire spectrum of curriculum development and quality assurance activities. It is therefore essential for Canadian higher-level education institutions (universities and colleges) to implement a systematic approach to graduate attributes assessment that fosters long-term sustainability and continuous improvement.

In this paper, we present COGAF (a Common Graduate Attributes management Framework). COGAF describes the components that should be taken into account when executing a graduate attributes assessment project. It is inspired by widely accepted enterprise architectures such as the Zachman framework [6], The Open Group Architecture Framework (TOGAF) [4], and the Department of Defense Architecture Framework (DODAF) [1]. These frameworks deal with the complex problem of aligning business goals with IT (Information Technology) in an organization by looking at various facets of the organization including corporate governance, stakeholders, process management, IT, etc.

COGAF is a simpler and more focused framework. It consists of a set of artifacts for integrating and managing the assessment (teaching and evaluation) of CEAB graduate attributes in a Canadian higher-level education institution. COGAF aims to align four equally important components: Governance, People, Process, and Technology.

- Governance: The objective is to provide strategic directions that serve as the basis for defining goals and objectives, performance measurement, policies and meta-processes, and quality controls.

- People: This component is concerned with setting the right conditions to motivate and train instructors, lab specialists, administrators, and other stakeholders, involved in the assessment effort.

\footnotetext{
${ }^{1}$ The full list of CEAB graduate attributes can be found on: http://www.engineerscanada.ca/accreditation-resources
} 
- Process: The focus of the process component is of the operational activities to carry out the tasks involved in graduate attributes assessment.

- Technology: The technology component provides a set of tools to support teams working on different assessment tasks at various levels (e.g., program, department, faculty) of the assessment process.

The design of COGAF follows four main criteria:

- Simplicity: The framework contains a limited set of artifacts that makes it manageable and most importantly practical. It draws from practical experience in integrating graduate attributes at Concordia University, more particularly in the ECE department.

- Extendibility: The framework is easily extendible, for example, by adding new artifacts.

- Portability: COGAF can be used by any higher-level education institution. It is not only specific to Concordia University.

- Openness: COGAF is an open framework and it is free to use. A website will be created shortly to allow participants to take full advantage of COGAF.

We discuss COGAF components in more detail in the remaining parts of the paper. We also provide examples from our own experience implementing some these concepts in ECE and, in occasions, in ENCS (The Faculty of Engineering and Computer Science) at Concordia University.

\section{COGAF Components}

Figure 1 shows COGAF architecture. In this paper, we discuss the core components of COGAF: Governance, People, Process, and Technology. The outcome of each component is a set of artifacts (documents, tools, figures, models, etc.) that need to be generated as part of a graduate attributes assessment project. Continuous improvement, guidelines and best practices, and maturity levels are other components of COGAF that ensure that the institution follows a long-term sustainable effort in integrating graduate attributes in their programs. These components are not discussed in this paper because of space limitation.

\subsection{Governance Component}

The definition of the term governance varies depending on the application domain. Perhaps, the most cited example of governance is the one of corporate governance, which broadly refers to the way corporations are managed and controlled [2]. The objective of the governance component in COGAF is somewhat similar in the sense that it refers to a set of basic mechanisms, rules, and processes that regulate the way by which an institution steers the graduate attributes assessment framework. The objective is to ensure a successful integration of graduate attributes in teaching, curriculum development, and accreditation.

Governance is led by a governance body that is formed during the initiation phase of the graduate attributes assessment project. It may contain the stakeholders who will lead the project at both the department and faculty levels. The definition of stakeholders and their roles is discussed later in the paper.

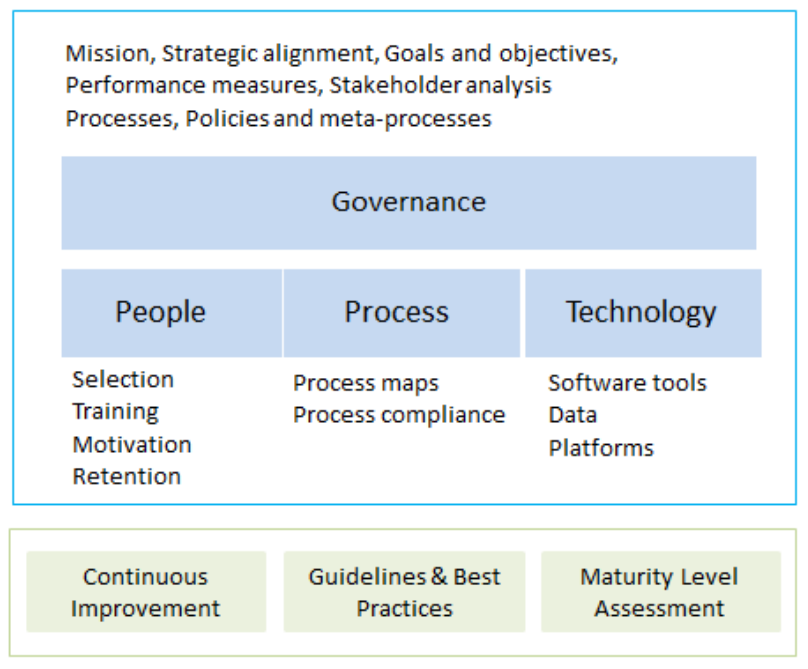

Fig. 1. COGAF Architecture

The outcomes of the COGAF governance component consist of the following artifacts: a mission statement, a strategic alignment statement, execution capability artifacts, and monitoring capability artifacts.

\section{Mission:}

The mission defines the fundamental purpose of undertaking a graduate attributes assessment project. The mission should be clearly stated to helps align people involved in the assessment project around a common goal. A mission should also infer the desired level of performance and commitment.

The mission can be defined at the level of an engineering department or at the faculty level ${ }^{2}$, depending on the size and complexity of the institution. It is, however, recommended to have a common mission across engineering departments (i.e., at the faculty level) to share experiences and resources.

\footnotetext{
${ }^{2}$ We assume that engineering departments are grouped under the Faculty of Engineering, which we believe it is the case in higher level institutions.
} 


\section{Strategic alignment:}

The aim of strategic alignment is to answer the following question: Is the mission of the graduate attributes assessment project aligned with the mission of the institution?

Strategic alignment ensures that the institution as a whole is working towards a common goal. It can also help win the buy-in from higher leadership such as the office of the academic vice-president. Since accreditation is an important requirement for all engineering schools in Canada, we believe that it is rather simple to justify the need for a COGAF project. Accreditation, however, should not be an end in itself, but a means to train highly qualified engineers equipped with the 12 graduate attributes. Concordia's mission is:

"Concordia University is welcoming, engaged, and committed to innovation and excellence in education, research, creative activity and community partnerships. It dares to be different and draws on its diversity to transform the individual, strengthen society and enrich the world." ${ }^{3}$

The current strategic plan of Concordia University further supports this mission by revolving around three main strategic directions, among which the first one is to reach: "High academic quality, with particular focus on research and creative activity; teaching and learning; and academic standards"

The adoption of graduate attributes is for improving the quality of education with a focus on engineering programs and as such the mission of a graduate assessment project at Concordia is fully aligned with the university's mission and strategic plan.

\section{Execution capability:}

The execution capability of COGAF consists of a number of artifacts to allow an institution to put COGAF in practice in order to achieve the stated mission. We suggest the following artifacts:

- Goals and objectives

- Performance measures

- Stakeholders

- Processes

- Policies and meta-processes

Goals and objectives represent the aims that an institution must pursue when implementing COGAF. The goals are high-level statements, whereas objectives must

\footnotetext{
${ }^{3}$ http://www.concordia.ca/content/dam/concordia/offices/vpdersg/docs/b oard-senate/Mission_Vision_Values.pdf

${ }^{4} \mathrm{http} / / /$ www.concordia.ca/about/strategic-framework.html
}

be precise and quantifiable. Goals and objectives must be aligned with the mission. Examples of goals include:

G1. Increase the number of Electrical and Computer engineering courses that assess graduate attributes

G2. Improve people involvement in graduate attributes assessment

G3. Increase student awareness of graduate attributes

Example of objectives that can be used to meet goal G1 are:

O1. Embed the 12 graduate attributes in all core electrical and computer engineering courses by fall 2017.

O2. Increase the number of core courses that assess non-technical skills, namely, communication skills, professionalism, ethics and equity, lifelong learning, and impact of engineering on society by $25 \%$ by fall 2017 .

O3. Introduce an engineering course dedicated solely to the use of tools by winter 2016 .

Once the objectives are set, performance measures are easy to derive. They are used to track and monitor the success of the graduate attributes assessment effort. A simple performance measure for $\mathrm{O} 1$ would be to measure the number of core courses that are being assessed every year until 2017. A successful project is the one where all performance measures are met. Monitoring should be done on a yearly (or perhaps a semester) basis so as to make adjustments if the performance is deemed not satisfactory. The list of performance indicators associated with each objective is another artifact of the governance component.

Another aspect of the execution of COGAF is to determine list of stakeholders who will operate the framework. Table 1 shows an example of a stakeholder matrix that defines typical stakeholders with their roles. Note that the undergraduate program director is a new position created in engineering departments at Concordia to deal with curriculum changes and graduate attributes. The role of academic advisors for undergraduate students is still maintained, and offered by the undergraduate program directors. The table shows an example of stakeholders. Other institutions may decide to have different stakeholders depending on the size and the culture of the institution.

When defining the role of stakeholders, it is common to assign a set of responsibilities to each member, using usually the RACI (Responsible, Accountable, Consulted, and Informed) responsibility assignment matrix [2]. The objective is to determine the responsibility of each stakeholder based on his or her level of involvement. We 
expect that each institution will have its own policies on how to assign these responsibilities.

A functional organizational structure is needed to describe how the activities are executed among the stakeholders that are responsible of governing and executing the graduate attributes assessment project.

At ENCS (the Faculty of Engineering and Computer Science at Concordia), we have a graduate attributes committee in each department, composed of selected faculty members, and chaired by the undergraduate curriculum director. This committee plays the role of a governance body at the department level. Another committee exists at the faculty level, chaired by the associate dean of academic programs. Members of this committee include the undergraduate curriculum directors. This committee governs the project at the Faculty level.

Table 1. Stakeholders and their roles in COGAF

\begin{tabular}{|l|l|}
\hline Stakeholder & Main Role \\
\hline $\begin{array}{l}\text { Dean of the Faculty } \\
\text { of Engineering }\end{array}$ & $\begin{array}{l}\text { Oversees the overall governance and } \\
\text { execution of the graduate attributes } \\
\text { assessment project, and allocates } \\
\text { resources as needed. }\end{array}$ \\
\hline $\begin{array}{l}\text { Associate dean of } \\
\text { academic programs }\end{array}$ & $\begin{array}{l}\text { Leads the day-to-day execution of the } \\
\text { assessment project at the Faculty level, } \\
\text { i.e., across departments, coordinates } \\
\text { the assessment effort across } \\
\text { departments. }\end{array}$ \\
\hline Department chairs & $\begin{array}{l}\text { Oversee the overall governance and } \\
\text { execution of the assessment project at } \\
\text { the department level, allocate resources } \\
\text { at the department level. }\end{array}$ \\
\hline $\begin{array}{l}\text { Undergraduate } \\
\text { Curriculum Directors }\end{array}$ & $\begin{array}{l}\text { Leads the day-to-day execution of the } \\
\text { assessment project at the department } \\
\text { level, coordinates the assessment } \\
\text { process with the Faculty. }\end{array}$ \\
\hline Administrative staff & $\begin{array}{l}\text { Provides administrative support such as } \\
\text { coordinating meetings. }\end{array}$ \\
\hline $\begin{array}{l}\text { Full-time and part- } \\
\text { time instructors }\end{array}$ & $\begin{array}{l}\text { Instructors oversee the assessment of } \\
\text { graduate attributes at the course (or } \\
\text { multiple courses) level. }\end{array}$ \\
\hline Lab specialists & $\begin{array}{l}\text { Oversee the assessment of graduate } \\
\text { attributes at the level of labs. }\end{array}$ \\
\hline Teaching assistants & $\begin{array}{l}\text { Oversee the assessment of graduate } \\
\text { attributes at the level of tutorials and } \\
\text { labs. }\end{array}$ \\
\hline $\begin{array}{l}\text { Involved in the assessment itself and } \\
\text { provide feedback on their learning } \\
\text { experience. }\end{array}$ \\
$\begin{array}{l}\text { Provide technical supports in the use of } \\
\text { tools and technology related to the } \\
\text { graduate attributes assessment project. }\end{array}$ \\
\hline antists
\end{tabular}

Part of the governance effort is to define a list of operational processes for a graduate attributes assessment project. For this, we suggest, as an artifact, a process matrix that contains the name of each process with a short description. Note that, at the governance level, only the process names and descriptions are needed, the details of each process (i.e., activities and flow of activities) are defined in the Process Component. Additional information about processes can be added such as process importance level (that can be ranked from high to low), process risk, etc. Table 2 shows an example of a list of processes.

\section{Table 2. Examples of COGAF processes}

\begin{tabular}{|l|l|}
\hline Process & Description \\
\hline $\begin{array}{l}\text { Mapping courses to } \\
\text { graduate attributes }\end{array}$ & $\begin{array}{l}\text { This process describes the steps } \\
\text { of mapping courses to graduate } \\
\text { attributes and indicators. }\end{array}$ \\
\hline $\begin{array}{l}\text { Making changes to } \\
\text { graduate attributes } \\
\text { assigned to a course }\end{array}$ & $\begin{array}{l}\text { This process describes the steps } \\
\text { of modifying graduate attributes } \\
\text { assigned to a course }\end{array}$ \\
\hline $\begin{array}{l}\text { Assessing graduate } \\
\text { attributes in a course }\end{array}$ & $\begin{array}{l}\text { This process describes the steps } \\
\text { that an instructor should follow to } \\
\text { assess graduate attributes in a } \\
\text { given course. }\end{array}$ \\
\hline $\begin{array}{l}\text { Reporting grades and } \\
\text { feedback }\end{array}$ & $\begin{array}{l}\text { This process describes the steps } \\
\text { of reporting grades and feedback } \\
\text { on an assessment. }\end{array}$ \\
\hline $\begin{array}{l}\text { Analysing assessment } \\
\text { results }\end{array}$ & $\begin{array}{l}\text { This process describes the steps } \\
\text { of analyzing the assessment of a } \\
\text { given graduate attribute in a } \\
\text { course or multiple courses. }\end{array}$ \\
\hline $\begin{array}{l}\text { Improving courses and } \\
\text { curriculums }\end{array}$ & $\begin{array}{l}\text { This process shows the steps of } \\
\text { implementing the course (or } \\
\text { curriculum) improvements } \\
\text { resulting from the assessment } \\
\text { effort. }\end{array}$ \\
\hline
\end{tabular}

\section{Policies, Meta-policies and monitoring capability:}

The governance body should also define a set of basic rules (policies and meta-processes) that govern how the various bodies of the assessment project operate. For example: how does a particular committee reach an agreement? What is the term of each committee member?

Finally, like in any other project, it is important to put a set of management processes in place to ensure proper execution of the graduate attributes assessment project. This can be done by having a simple internal control mechanism by frequently checking on the progress of the assessment project. One way of achieving this is to have a checkpoint list that can be sent to every instructor to report on progress. Another way is to dedicate an item to discuss progress at the department councils.

\subsection{People Component}

The people component deals with matters related to the selection, training, motivation, and retention of the stakeholders who will operate COGAF. 
The first artifact of the people component is a list of individuals who are assigned the roles defined in the stakeholder's list. For example, at Concordia, the first author of the paper is currently the ECE Undergraduate Curriculum Director, the second author is the ECE Department chair, and the third author is the associate dean of academic programs. All three of us are actively engaged in graduate attributes assessment at various capacities at both the Department and Faculty levels.

The criteria for selecting individuals may vary from one institution to another. It is reasonable to assume that individuals involved in the governance and execution of the graduate attributes assessment project should be Faculty members with experience and knowledge of the curriculum. Active involvement in the academic life should also be considered.

Training of stakeholders is another important aspect of the people component of COGAF. Many graduate attributes require expertise in areas that stretch beyond the common engineering topics that most instructors and students are familiar with. In fact, one may argue that except for some graduate attributes such as knowledge base, design, problem analysis, and perhaps investigation, all other attributes such as communication skills, professionalism, life-long learning, impact of engineering on society, etc. may be challenging to integrate in engineering courses. Training instructors (both full-time and part-time), lab specialists, and teaching assistants on these attributes is, therefore, highly desirable. Training can be done internally (incurring minimum cost) by involving other instances of the institution that specialize in such domains. At ECE, we find it useful to work with the Center of Engineering in Society (CES), an ENCS department that provides complementary engineering education to help students improve their communication skills, professionalism, and understand the ethical dimensions of engineering. CES faculty members also conduct research in many of these areas. CES has been very useful in providing guidance in teaching and evaluating communication skills, professionalism, ethics and equity, and impact of engineering on society.

Two other resources are the Concordia Center of Teaching and Learning Services (CLTS) and the Co-op Institute. CLTS is home for many experts in various areas of education. CLTS was involved earlier in the graduate attribute assessment effort by helping with the definition of indicators and the associated learning objectives. Recently, we have started to work with the Co-op institute to understand the learning opportunities offered to students in an industrial environment. Many of these opportunities touch on topics related to graduate attributes such as communication skills and professionalism.

Motivation is another important aspect of the people component that, if not dealt with properly, may put the execution of the project at risk. Smooth integration of graduate attributes in a course or a program is not that straightforward, which understandably leads to resistance to change. We should not underestimate the impact of instilling graduate attributes on teaching and curriculum development. COGAF suggests using change management techniques (e.g., [3]) to reduce resistance to change. The first step is to identify what causes the resistance to change. In our experience (not only at Concordia but also in other institutions), resistance to change seems to be due to three main reasons: (a) the lack of understanding of the benefits of graduate attributes in training of highly-qualify engineers compared to the traditional way of teaching, (b) the workload associated with redesigning courses and other tasks related to integrating graduate attributes, and (c) the lack of a methodology and supporting tools for integrating graduate attributes from an end-to-end perspective. The main objective of designing COGAF is to address Point (c).

Point (a) can be addressed by organizing workshops to raise awareness as to the importance of the explicit teaching and evaluation of the 12 attributes. The keyword here is 'explicit'. This is because many courses do already embed some of the attributes (e.g., design, and problem analysis), but do so (in most cases) implicitly. These workshops should also provide clear examples on how students would benefit from these skills in a workplace, for example, by looking at what employers value in addition to knowledge base.

To address Point (b), we suggest a number of strategies. The first one is to identify motivated instructors to act as agents of change, for example, by taking the initiative of redesigning course outlines to include graduate attributes, designing assignments and exams, etc. This should reduce some of the workload. The second strategy is to start by selecting a small number of courses and graduate attributes and go through one full assessment iteration. Hopefully, the result can lead to course or curriculum improvements. This will motivate the rest of the department to embark on the project. The next iterations are expected to focus on a larger scope until all attributes are covered.

\subsection{Process Component}

The main focus of the process component is to map (model) the processes defined at the governance level. A process map is a flowchart of the process activities. Process maps can help later identify opportunities for process improvement. They are also a good way to document the activities taken place for the purpose of accreditation. Depending on the processes, the mapping can be done by the graduate attributes committee at the department or the governance body at the faculty level.

There are several notations that can be used to map processes. COGAF recommends using standard process 
mapping notations such as $\mathrm{BPMN}^{5}$ (Business Process Management Notation). BPMN has a rich set of constructs that can express activities, events, data, etc. BPMN has also large community support and toolsets; many of these tools are free and open source. Figure 2 shows an example of a process map for the 'Reporting grades and feedback of assessing graduate attributes in a course' process. The process starts by having the course instructor collect grades related to graduate attributes from different sources (exams, assignments, projects, etc.), normalize grades, analyze grades, add feedback, and submit grades and feedback to the graduate attributes committee.

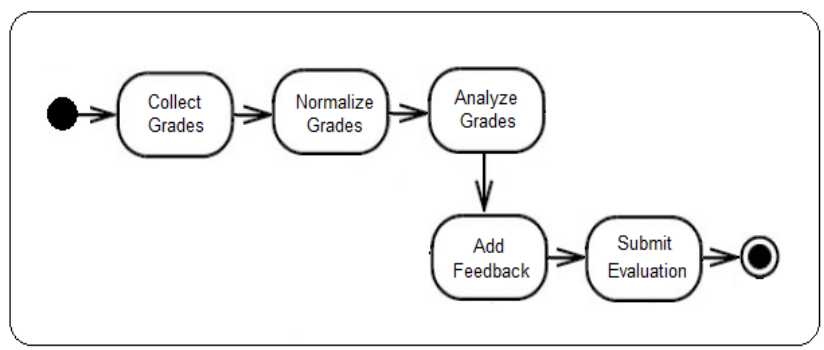

Fig. 2. An example of a process

After all the processes are mapped, we recommend keeping track of the input and output data for each process. For example, in the above process, the input data is grades from different sources and the output data consists of (a) normalized grades, and (b) written feedback that reflects the instructor's opinion on the performance of students in the graduate attributes in question. It is useful to clearly indicate the activities for which the outcomes are needed for accreditation to prepare for accreditation. These activities should be labelled as process compliance points to clearly distinguish them from other activities. They should be frequently monitored to make sure they are executed properly. Finally, COGAF recommends having an additional artifact that shows the relationship between processes and stakeholder to keep track of who does what.

\subsection{Technology Component}

The objective of the technology component is to provide tool support. By tool, we mean software applications, spreadsheets, forms, template, or any other instrument that can automate the tasks involved in the graduate attributes assessment project. The technology component should also address the technological platforms (web-based, hosted on the cloud, etc.) that need to be used. IT professionals are important stakeholders in the technology components.
Typical tools should include a data repository, a data extraction component, and a data analysis and visualization component. The key component of a graduate attributes assessment projects is the results of the evaluations such as grades, feedback, etc. These must be stored in a repository that optimizes storage, retrieval and processing of very large data.

There is also a need for data reporting tools that are easy to use by instructors. Instructors should not worry about how the grades should be formatted or entered. The ideal situation would be to have a tool that easily integrates with existing practices of instructors. Note that this does not only apply to reporting grades, but also to designing course outlines with graduates attributes, etc. It would be beneficial to have a graduate attributes management tool suite that is embedded with the course management tool used by the instructors. This way, instructors do not have to change environments. Besides, this reduces the time it takes to learn a new tool.

The analysis of assessment results requires data analysis capabilities, similar to those used in business intelligence. These tools should show different types of correlations, and allow the graduate attributes committees to do different type of data analytics.

\section{Conclusion}

We presented COFAG, a framework that can be used by higher-level education institutions to manage the integration of graduate attributes assessment in their programs. COGAF is open and free. We hope to have the community contribute to it by sharing experiences and best practices. This way, COGAF can become a standard way of managing graduate attributes.

\section{References}

[1]. D. E. Wisnosky, DoDAF Wizdom: A Practical. Wizdom Press, 2004, 257 pp. \{ISBN-10: 1893990095\}

[2]. D. Cleland, L. Ireland, Project management: strategic design and implementation. McGraw-Hill Professional. 2006, 523 pp. \{ISBN-10: 007147160X\}

[3]. J. P. Kotter, Leading Change. Harvard Business Review Press, 2012, 208 pp. \{ISBN-10: 1422186431\}

[4]. V. Haren, Togaf Version 9.1. Van Haren Publisher, 2011, 654 pp. \{ISBN-10: 9087536798$\}$

[5]. R. A. G. Monks, Nell Minow, Corporate Governance. Wiley, 2011 (5th ed.), 542 pp. \{ISBN-10: 0470972599\}

[6]. C. O'Rourke, N. Fishman, W. Selkow, Enterprise Architecture Using the Zachman Framework. Course Technology Ptr, 2003, 716 pp. \{ISBN 0619064463\}

\footnotetext{
${ }^{5}$ http://www.bpmn.org/
} 